NBER WORKING PAPER SERIES

\title{
VOLATILITY, EMPLOYMENT AND THE PATTERNS OF FDI IN EMERGING MARKETS
}

\author{
Joshua Aizenman \\ Working Paper 9397 \\ http://www.nber.org/papers/w9397 \\ NATIONAL BUREAU OF ECONOMIC RESEARCH \\ 1050 Massachusetts Avenue \\ Cambridge, MA 02138
}

December 2002

This paper was presented at the NBER IASE seminar (Monterrey, Mexico), November 2002. I would like to thank Sebastian Edwards, Hugo Maul, and the conference participants for useful comments. The views expressed herein are those of the authors and not necessarily those of the National Bureau of Economic Research.

(C) 2002 by Joshua Aizenman. All rights reserved. Short sections of text not to exceed two paragraphs, may be quoted without explicit permission provided that full credit including, $\odot$ notice, is given to the source. 
Volatility, employment and the patterns of FDI in emerging markets

Joshua Aizenman

NBER Working Paper No. 9397

December 2002

JEL No. F21, F23

\begin{abstract}
$\underline{\text { ABSTRACT }}$
The purpose of this paper is to explore the implications of the deepening presence of multinationals in emerging markets on the cost of macroeconomic volatility there. We find that macroeconomic volatility has a potentially large impact on employment and investment decisions of multinationals producing intermediate inputs in developing countries. This is the case even for risk neutral multinationals, as their profit function is non-linear due to price and productivity effects. For industries with costly capacity, the multinationals would tend to invest in the more stable emerging market/s. Higher volatility of productivity shocks in an emerging market producing the intermediate inputs reduces the multinationals' expected profits. High enough instability in such a market would induce the multinationals to diversify intermediate inputs production, investing in several emerging markets. This effect is stronger in lower margin industries. We identify circumstances where this diversification is costly to emerging markets. Such a diversification increases the responsiveness of the multinationals' employment in each country to productivity shocks, channeling the average employment from the more to the less volatile location, and reducing the multinationals' total expected employment in emerging markets.
\end{abstract}

Joshua Aizenman

Department of Economics, UCSC

217 Social Sciences 1

1156 High Street

Santa Cruz, CA 95064

and NBER

jaizen@ucsc.edu 


\section{Introduction}

The purpose of this paper is to investigate the investment patterns of multinationals having the opportunity to locate the production of intermediate input in low wage emerging markets. We study the impact of volatility on the patterns of the multinationals' employment and investment, and identify conditions under which multinationals are induced to diversify the production of the intermediate input by investing in several emerging markets. Such a production strategy may be viewed as a hybrid of vertical and horizontal patterns, and may mitigate the adverse consequences of volatility on multinationals' expected profits. A by-product of this strategy is increasing the volatility of employment, and reducing the expected multinationals' employment in emerging markets. In these circumstances, greater stability of an emerging market is associated with higher quasi rents.

Consequently, one expects that the potential diversification by multinationals would increase the demand for macroeconomic stability in emerging markets.

This paper is motivated by the large increase of foreign direct investment (FDI) in emerging markets during the last decades. A good example of this process is Mexico, where in 1989-1993, the compensation to manufacturing workers employed by multinationals almost doubled (in \$US terms), their number increased by about $50 \%$, and the stock of manufacturing FDI almost tripled [see Figure 1, reporting employment, compensation and FDI in Mexican manufacturing, 1989-1993]. The large wage gap between the U.S. and Mexico suggests that vertical FDI dominates the inflow of FDI to Mexico. ${ }^{1}$

A useful paradigm explaining FDI is found in Markusen and Maskus (2001), surveying recent studies of FDI that adopt a general-equilibrium trade-theoretic view of the multinational. They also provide a useful overview of a model where firms choose endogenously between vertical and horizontal production structures when investing abroad. A vertical pattern arises when the multinational firm fragments the production process internationally, locating each stage of production in the country where it can be done at the least cost. A horizontal pattern occurs when the multinational produces the same product or service in multiple countries. Markusen and Maskus note that the choice between vertical

1 See Feenstra and Hanson (1997) for further discussion of Mexico's Maquiladoras. 
and horizontal production structures depends on country characteristics, such as relative size and relative endowment differences, as well as trade and investment costs. ${ }^{2}$

Most of the trade-theoretic FDI literature [including the papers reviewed by Markusen and Maskus (2001)] relies on non-stochastic models. ${ }^{3}$ Aizenman and Marion (2001) showed that volatility tends to encourage horizontal patterns, and discourage vertical patterns of FDI. This was shown in a model where there is an exclusive choice between these two patterns of investment. The present paper extends this approach by allowing for a hybrid model, where the multinational considers horizontal investment at the upstream stages of a vertical production chain. Focusing on uncertainty is important because emerging markets are characterized by much greater uncertainty than the OECD countries. ${ }^{4}$

The results of this paper are consistent with the notion that macroeconomic volatility has a large adverse impact on employment decisions and on the profitability of

2 When the industrial-organization approach to trade was first applied to the multinational, researchers developed separate vertical and horizontal models to describe firm behavior. See Helpman (1984) and Helpman and Krugman (1985) for examples where vertical models were used; see Markusen (1984) and Brainard (1997) for examples where horizontal ones were employed. Eventually, the two approaches were integrated in a "knowledge-capital model." Markusen and Maskus (2001) describe this integrated approach and highlight its three assumptions about technology:

(a) The location of knowledge-based assets may be fragmented from production;

(b) Knowledge-based assets are skilled-labor intensive relative to final production; and

(c) The services of knowledge-based assets are joint inputs into multiple production facilities.

Properties (a) and (b) motivate vertical multinationals, whereas (c) gives rise to horizontal patterns. See Carr, Markusen and Maskus (2001) for an empirical test of the knowledgecapital model.

${ }^{3}$ See Dunning (1993) for a good overview of the earlier literature. There are a few papers that examine FDI in a stochastic setting. For example, Aizenman (1994) studies the effects of exchange-rate volatility on horizontal FDI. Spiegel (1994) examines the impact of sovereign risk on FDI inflows compared to portfolio investment. Goldberg and Kolstad (1995) study the effects of real exchange-rate uncertainty on FDI under risk aversion and use U.S. bilateral FDI flows to confirm their prediction that higher real exchange rate volatility increases FDI. Wei (1997) identifies the adverse effects of corruption-induced uncertainty on FDI. Froot and Stein (1991), Klein and Rosengren (1994) and Blonigen (1997) evaluated other links between the exchange rate and FDI, including the wealth and relative wage channels.

${ }^{4}$ See Hausmann and Gavin (1995). 
multinationals producing intermediate inputs in emerging markets. This is the case even for risk neutral multimillions, as their profit function is non-linear due to price and productivity effects. For industries with costly capacity, the multinational would tend to invest in relatively stable emerging market/s. We show that higher volatility of productivity shocks in an emerging market producing the intermediate inputs reduces the multinationals' expected profits. High enough instability in such a market would induce the multinationals to diversify its production of intermediate inputs, investing in several emerging markets. This effect is stronger in lower margin industries. Such diversification increases the responsiveness of the multinationals' employment to productivity shocks, channeling the average employment from the less to the more stable location. These results stem from the limited substitutability of the various production stages in a vertical production mode, and do not hold for the case of a horizontal production. The diversification of intermediate goods production increases the multinationals' responsiveness to adverse shock, reducing thereby the adverse effects of macroeconomic volatility on the multinationals' expected profits, and reducing the expected multinationals' employment in emerging markets.

The rest of the paper is organized as follows. Section 2 lays out the stochastic model, specifying the two feasible modes of FDI: a non-diversified production of intermediate inputs and a diversified production mode. We examine the impact of productivity shocks on the profits and employment under the two FDI modes. Section 3 identifies the conditions leading the multinational to switch from a non-diversified to a diversified production mode. Section 4 concludes, and the Appendix derives some key equations used in the analysis. 


\section{The Model}

We consider a global economy composed of 3 countries, $\mathrm{H}, \mathrm{F}_{1}$ and $\mathrm{F}_{2}$, each consuming two final goods, $Y$ and $Z$. Consumers utility is a semi-additive function of the two goods

$$
U=Z+\frac{A}{\delta}[Y]^{\delta}, \quad 0<\delta<1 .
$$

Henceforth we will refer to country $\mathrm{H}$ as the home country, and countries $\mathrm{F}_{1}$ and $\mathrm{F}_{2}$ as the emerging markets. We will assume that, due to reasons outside the present model's scope, the multinational's final production stage is at country $\mathrm{H}$, whereas the intermediate product $\mathrm{M}$ would be produced in the emerging markets.

The supply of labor in each country is inelastic:

$$
L^{s}=\bar{L} ; \quad L_{i}^{s^{*}}=\bar{L}_{i}^{*} ; \quad i=1,2
$$

We normalize the price of good $Z$ to one. Good $Z$ is produced in all the countries using a simple Ricardian technology:

$$
Z=L_{z}, \quad Z_{i}^{*}=a_{i}^{*} L_{z, i}^{*} \quad i=1,2 .
$$

where the parameter $a_{i}^{*}$ is the productivity of foreign labor. Hence, the real wage is

$$
w_{i}^{*}=a_{i}^{*} .
$$

Good $Y$ is produced by a monopoly using a vertical production line, where the production is fragmented geographically. The final production stage is done in the $\mathrm{H}$ economy, using intermediate inputs $\mathrm{M}$ that are produced in the emerging markets at an earlier stage. Specifically, assume that the intermediate input can be produced in each of the foreign countries using a Cobb-Douglas production technology 


$$
M_{i}=\left(1+\varepsilon_{i}^{*}\right) b_{i}^{*} \sqrt{L_{M, i}^{*}} ; \quad i=1,2
$$

where $L_{M, i}^{*}$ is the labor employed, $b_{i}^{*}$ is labor productivity in the foreign intermediate-good sector, and $\varepsilon_{i}^{*}$ is a mean zero productivity shock in country $\mathrm{i}$, uncorrelated with other shocks. The final production stage in country $\mathrm{H}$ combines the intermediate input $M$ with the services produced by domestic labor using a Leontief technology:

$$
Y=\operatorname{Min}\left\{M_{1}+M_{2} ;(1+\varepsilon) b \sqrt{L_{y}}\right\} ; \quad E(\varepsilon)=0 ; \quad \operatorname{cov}\left(\varepsilon ; \varepsilon_{i}^{*}\right)=0 ; \quad i=1,2
$$

where $L_{y}$ is the $\mathrm{H}$ labor employed in sector Y. To simplify, we assume that the labor force is competitive and homogenous. An alternative specification would allow labor employed by the multinational to supply heterogeneous skills, as in Rosen (1978). In these circumstances, all the infra marginal workers employed by the multinational would earn a quasi rent for their skills, and higher multinational employment would increase labor's quasi rent. See Appendix B for an outline of such an extension.

In order to focus on the impact of uncertainty, we assume zero transportation costs. Hence, proximity to the consumer does not play a role in determining production patterns. The intermediate good is produced before the final good. The monopoly must pre-commit the investment strategy prior to the realization of shocks. The monopoly is risk neutral and chooses the production strategy that maximizes its expected profit. Applying (1), the demand for good $Y$ in each country is

$$
Y^{d}=\left(A / P_{y}\right)^{\eta} ; \quad \eta=\frac{1}{1-\delta}>1
$$

Hence, the total demand facing the multinational is $3 Y^{d}$. We calculate employment and profit for the multinational engaged in vertical FDI, assuming that domestic and foreign productivity shocks are observed simultaneously. 
The multinational can follow two production modes:

I. Vertical production with no horizontal diversification: intermediate input $\mathrm{M}$ is

produced only in one of the emerging markets. Henceforth we refer to this production structure as mode $I$.

II. Vertical production with horizontal diversification of the intermediate output: the intermediate input $\mathrm{M}$ is produced in both emerging markets. Henceforth we refer to this production structure as mode II.

The capacity cost of mode $I$ is $C$. The capacity cost of mode $I I$ is $C(1+f)$; where $f$ is the percentage increase in the investment cost due to the diversification of $\mathrm{M}$ production. The profits associated with the two production modes are

$$
\begin{gathered}
\Pi_{I}=3 Y^{d} P_{y}-L_{y}-w_{1}^{*} L_{M, 1}^{*}-C \\
\Pi_{I I}=3 Y^{d} P_{y}-L_{y}-w_{1}^{*} L_{M, 1}^{*}-w_{2}^{*} L_{M, 2}^{*}-C(1+f)
\end{gathered}
$$

where we assume, for concreteness, that in mode $I$ the intermediate input is produced in country 1 .

We proceed with the analysis in three stages: first, we study the case of pure vertical production (mode $I$ ). Next, we study the case of vertical production with diversification of the intermediate output (mode $I I$ ). Finally, we contrast the two in order to determine the conditions explaining the choice of production mode made by the multinational. 


\subsection{Vertical production, without diversification.}

To fix ideas, we assume that in mode $I$ the multinational invests in country one. In the Appendix we show that the multinational's expected profits and employment in the emerging market are

$$
\begin{aligned}
& E\left[\Pi_{I}\right]=k_{I} E\left[\left\{\theta_{I}(1+\varepsilon)^{-2}+\theta_{I}^{*}\left(1+\varepsilon_{1}^{*}\right)^{-2}\right\}^{-\phi}\right]-C ; \\
& E\left[L_{M, 1}^{*}\right]=L_{M, 1}^{0} E\left[\left\{\theta_{I}(1+\varepsilon)^{-2}+\theta_{I}^{*}\left(1+\varepsilon_{1}^{*}\right)^{-2}\right\}^{-2 \phi / \delta}\left(1+\varepsilon_{1}^{*}\right)^{-2}\right]
\end{aligned}
$$

where $\phi=\frac{\eta-1}{\eta+1} ; \quad k_{I}>0 ; \theta_{I}+\theta_{I}^{*}=1$. The term $\phi$ measures competitiveness, and is bounded between zero (monopoly with unitary elasticity of demand) and 1 (prefect competition). Increasing $\phi$ implies more elastic demand, reducing thereby margins. ${ }^{5}$ The term $k_{I}$ is a constant. The weights $\theta_{I} ; \theta_{I}^{*}$ reflect the share of labor cost of each country, as is determined by the productivity and the wage of the two countries. ${ }^{6}$ The term $L_{M, 1}^{0}$ is the demand for labor employed in producing $\mathrm{M}$ when all shocks are zero.

\section{Expected employment, Expected profits and foreign productivity shocks}

We turn now to evaluate the impact of random productivity in the emerging market on expected employment and expected profits. For notation simplicity, we assume equal

\footnotetext{
${ }^{5}$ Applying (7), the margin is determined by $\left[P_{y}-M C\right] / P_{y}=0.5(1-\phi) / \phi$.

${ }^{6}$ Equation (10) assumes that the production of $M$ takes place after the realization of productivity shocks in both locations. If the production of $M$ takes place before the realization of the domestic productivity shock, the expected profit is
} $E\left[\Pi_{I}\right]=k_{I} E\left[\left\{\theta_{I} E\left[(1+\varepsilon)^{-2}\right]+\theta_{I}^{*}\left(1+\varepsilon_{1}^{*}\right)^{-2}\right\}^{-\phi}\right]-C$. The main results hold for either scenario. 
labor cost shares: $\theta_{I}=\theta_{I}^{*}=0.5$, and assume stable productivity in country $\mathrm{H}$. A second order Taylor approximation of (10) and (11) implies that

$$
\begin{gathered}
E\left[\Pi_{I}\right] \cong k_{I}\left[1-0.5 \phi(2-\phi) V_{\varepsilon_{1}^{*}}\right]-C \\
E\left[L_{M, 1}^{*}\right] \cong L_{M, 1}^{0}\left[1+V_{\varepsilon_{1}^{*}}\left\{2(\phi / \delta)^{2}-6(\phi / \delta)+3\right\}\right]
\end{gathered}
$$

where $V_{z}$ stands for the variance of variable z. Applying the above we characterize the profits and employment under mode $I$ :

\section{Proposition 1:}

a. More volatile productivity shocks in the emerging market producing $M$ reduces the multinational's expected profits.

b. If the margins are low [i.e., if the demand for the final product is relatively elastic, $\eta>\sqrt{3}$ ], higher volatility of shocks in the emerging market reduces the expected employment in sector M. The opposite holds for high margin industries.

\subsection{Vertical production, with intermediate input diversification (mode $I I$ ).}

Intermediate input diversification implies that the multinational will allocate the employment between the two emerging markets in order to minimize the cost of production. The resultant expected profits and employment are (see the Appendix for further details):

$$
E\left[\Pi_{I I}\right]=k_{I I} E\left[\left\{\theta_{I I}(1+\varepsilon)^{-2}+\theta_{I I}^{*}\left\{\left(1+\varepsilon_{1}^{*}\right)^{2} \lambda_{1}^{*}+\left(1+\varepsilon_{1}^{*}\right)^{2} \lambda_{2}^{*}\right\}^{-1}\right\}^{-\phi}\right]-C(1+f)
$$




$$
\begin{aligned}
& E\left[L_{M, 1}^{*}\right]= \\
& L_{M, 1}^{0, d} E\left[\left\{\theta_{I I}(1+\varepsilon)^{-2}+\theta_{I I}^{*}\left[\left(1+\varepsilon_{1}^{*}\right)^{2} \lambda_{1}^{*}+\left(1+\varepsilon_{2}^{*}\right)^{2} \lambda_{2}^{*}\right]^{-1}\right\}^{-2 \phi / \delta} \frac{\left(1+\varepsilon_{1}^{*}\right)^{-2}}{\left(1+\varepsilon_{1}^{*}\right)^{2} \lambda_{1}^{*}+\left(1+\varepsilon_{2}^{*}\right)^{2} \lambda_{2}^{*}}\right]
\end{aligned}
$$

where $k_{I I}$ is a constant $\left(k_{I I}=(4 / 3){ }^{\phi} K_{I}\right)$, and $\lambda_{1}^{*} ; \lambda_{2}^{*} ; \theta_{I I} ; \theta_{I I}^{*}$ are positive weights, $\lambda_{1}^{*}+\lambda_{2}^{*}=1 ; \quad \theta_{I I}+\theta_{I I}^{*}=1$, and $L_{M, 1}^{0, d}$ is the demand for labor employed by sector $\mathrm{M}$ in country 1 under the diversified production, when all shocks are zero. For notation simplicity we study the case where the labor cost share of the various countries is identical: $b^{2}=\left(b_{1}^{*}\right)^{2} / w_{1}^{*}=\left(b_{2}^{*}\right)^{2} / w_{2}^{*}$, and $V_{\varepsilon_{1}^{*}} \leq V_{\varepsilon_{2}^{*}}^{*}$

Applying (12) and (13) we infer that the second order approximation is:

$E\left[\Pi_{I I}\right] \cong k_{I I}\left\{1-0.125 \phi(1-\phi)\left[V_{\varepsilon_{1}^{*}}+V_{\varepsilon_{2}^{*}}\right]\right\}-C(1+f)$

$$
E\left[L_{M, 1}^{*}\right] \cong L_{M, 1}^{0, d}\left\{1-a_{1} V_{\varepsilon_{1}^{*}}+a_{2} V_{\varepsilon_{2}^{*}}\right\}
$$

where

$$
\begin{aligned}
& a_{1}=2-\frac{4}{3}\left[\frac{5-3 \delta}{2-\delta}\right]^{2}-\frac{8}{3} \frac{5-3 \delta}{2-\delta}-\frac{2}{3} \frac{(4-3 \delta)(1-\delta)}{2-\delta} ; \\
& a_{2}=\left\{\frac{4-\delta}{2-\delta}\left[\frac{5-3 \delta}{3}\right]^{2}-\frac{5-3 \delta}{3}-\frac{2}{3}(4-3 \delta)(1-\delta)\right\} \frac{2}{2-\delta}
\end{aligned} .
$$

It is easy to verify that for $0 \leq \delta \leq 1, a_{1}>0 ; a_{2}>0$.

Applying the above we characterize the profits and employment under mode II:

\section{Proposition 2:}

- Higher volatility of productivity shocks in the emerging market $\left(\varepsilon_{1}^{*}\right.$ or $\left.\varepsilon_{2}^{*}\right)$ reduces the multinational's expected profits. 
- The direct employment effect of volatility is negative: higher volatility of productivity shocks in emerging market 1 reduces the expected employment in sector $\mathrm{M}$ in that economy, independently of the elasticity of demand for the final product. The cross effect of volatility on employment is positive: higher volatility of productivity shocks in emerging market 2 increases the expected employment in emerging market 1 . This follows from the observation that diversification increases the responsiveness of the multinational to productivity shocks, channeling the average employment from the less to the more productive location.

We turn now to a comparison of the two production modes, focusing on the impact of productivity shocks in the emerging market.

3. The choice of production mode and the volatility of productivity shocks.

Proposition 1 implies that if the multinational would choose to produce the intermediate product $\mathrm{M}$ only in one location, it would choose the more stable emerging market. In the absence of volatility, the multinational's rate of return in the production mode $I$ is denoted by $\rho$ :

$$
\rho=\frac{k_{I}}{C}-1 .
$$

Appling this notation to $\left(10^{\prime}\right)$ and $\left(12^{\prime}\right)$ we infer that the multinational would prefer diversification (production mode $I I$ ) if the percentage increase in the capacity cost, normalized by the rate of return $\rho$, falls short of the increase in expected profits induced by the switch from mode $I$ to mode $I I$, denoted by $G$ :

$$
\frac{f}{1+\rho}<G
$$

where $G=\left[\frac{4}{3}\right]^{\phi}-1+0.5 \phi\left\{\left[(2-\phi)-0.25(1-\phi)\left[\frac{4}{3}\right]^{\phi}\right] V_{\varepsilon_{1}^{*}}-0.25(1-\phi)\left[\frac{4}{3}\right]^{\phi} V_{\varepsilon_{2}^{*}}\right\}$. 
Equation (14) allows us to characterize the conditions inducing the multinational to diversify the production of $\mathrm{M}$ :

- When productivity is stable, production mode $I I$ is preferable only if the percentage increase of the investment cost induced by the diversification, discounted by $\rho$, falls short of the extra profits attributed to the increase in output, $\left[\frac{4}{3}\right]^{\phi}-1$. This condition is less likely to hold for high margin industries, where $\phi$ is closer to zero.

- With volatile production, the gains from diversification are higher in more competitive industries, and

$$
d G / d \phi>0 ; \quad G_{\mid \phi=0}=0 ; \quad G_{\mid \phi=1}=\frac{1}{3}+0.5 V_{\varepsilon_{1}^{*}} .
$$

In perfectly competitive industries, the diversification mode would be preferred if the percentage gain in profits attributed to the extra capacity $(1 / 3)$, plus the gain associated with mitigating the exposure to volatility in the first emerging market (half the variance of productivity) exceeds $\frac{f}{1+\rho}$.

- $\quad$ As long as $\frac{f}{1+\rho}>G$, the multinational would prefer mode $I$, producing $\mathrm{M}$ in country $F_{1}$. In these circumstance the effect of higher volatility of productivity in $F_{1}$ is summarized by the following statement:

\section{Proposition 3:}

Higher volatility of productivity shocks in the emerging market producing $\mathrm{M}$ increases the likelihood of M diversification. This effect is stronger in lower margin industries [i.e., where $\phi$ is closer to one]. Higher volatility of the second emerging market reduces the likelihood of $\mathrm{M}$ diversification. The diversification of intermediate goods production reduces the expected multinationals' total employment in emerging markets. 
Explanation:

Note that

$$
\begin{aligned}
& \frac{\partial G}{\partial V_{\varepsilon_{1}^{*}}}=0.5 \phi\left[(2-\phi)-0.25(1-\phi)\left[\frac{4}{3}\right]^{\phi}\right]>0 ; \\
& \frac{\partial G}{\partial V_{\varepsilon_{2}^{*}}}=-0.5 \phi 0.25(1-\phi)\left[\frac{4}{3}\right]^{\phi}<0 \\
& \frac{\partial^{2} G}{\partial \phi \partial V_{\varepsilon_{1}^{*}}}=1-\phi-0.25[4 / 3]^{\phi}(0.5-\phi)>0 .
\end{aligned}
$$

More volatile productivity in the country producing M reduces the multinational profits under both modes. Yet, the drop in profits is larger in the non-diversified mode. Hence, diversification provides a natural hedge against volatility. This effect is lower in high margin industries; as the price adjustment induced by the drop in output due to adverse shocks mitigates the drop in profitability. For high enough volatility and low enough margins, the multinational prefers the $\mathrm{M}$ diversification mode. Unlike the case of mode $I$, with diversified production, higher volatility reduces the expected employment in producing $M$ independently of the elasticity of demand.

The decline of the expected multinational's total employment in emerging markets induced by M diversification reflects the trade off between capital and labor, and holds for all $\eta .^{7}$ The diminishing marginal productivity of labor and the downwards sloping demand facing the multinational implies that diversification induces the multinational to increase total output. This is accomplished by relying more on capital and less on labor services.

\footnotetext{
${ }^{7}$ This point can be illustrated by noting that in the absence of uncertainty, the ratio of the multinational's total employment in the emerging markets in mode $I I$ compared to mode $I$ is $0.5[4 / 3]^{2 /(2-\delta)}<1$. The corresponding ratio of Y production in mode $I I$ compared to mode $I$ is $[4 / 3]^{1 /(2-\delta)}>1$ [see Appendix A for further details]. Adding uncertainty does not change the qualitative nature of these results.
} 


\subsection{Simulation}

We close our discussion with two simulations. Figure 2 corresponds to the case where the demand for the product is relatively elastic $(\eta=4)$. The top panel reports the expected profits, net of the investment cost, drawn against the standard deviation of the productivity shocks impacting country $\mathrm{F}_{1}$. This is done for the simplest distribution, where the future productivity may be high or low, with equal probability. The bottom panel reports the expected employment in country $\mathrm{F}_{1}$. The solid lines in Figure 2 correspond to the mode $I$ [pure vertical production], whereas the dotted line corresponds to mode $I I$ [vertical production with $\mathrm{M}$ diversification]. The expected profits are reported as a fraction of mode's $I$ profits in the absence of volatility.

Similarly, the expected employment is reported in the lower panel as a fraction of the employment in mode $I$, in the absence of volatility. For low volatility, mode $I$ is superior to mode II. As the volatility of the emerging market increases, both the expected employment there and the multinational's expected profits decline. For high enough volatility, the multinational would diversify the production of the intermediate output. The volatility threshold inducing diversification corresponds to the vertical broken line. The diversification reduces sharply the employment in sector $M$ in the country where $M$ was produced exclusively, $\mathrm{F}_{1}$. It has also the effect of reducing the responsiveness of the expected profits and employment to further increase in volatility. Figure 3 reports the simulation for the case where the demand is relatively inelastic $(\eta=1.33)$. The overall effect of volatility is similar to the one in Figure 2, with the exception that higher volatility increases initially the expected employment in mode $I$, though this effect is very small. As in Figure 2, for high enough volatility the multinational would diversify the production of the intermediate input, cutting sharply the employment in sector $\mathrm{M}$ in $\mathrm{F}_{1}$.

Note that in both cases (Figures 2 and 3), the diversification reduces the total multinational's employment in the emerging markets. Hence, the expected employment and income gains of country $F_{2}$ fall short of the losses of country $F_{1}$. 


\section{4. $\quad$ Concluding remarks}

This paper focused on the impact of volatile productivity on the multinational's production patterns in emerging markets. This was done for the case where the multinational fragments the production -- the final output uses intermediate inputs produced in a low wage emerging market. We show that higher volatility in the emerging market has adverse consequences on the multinational's profitability, as well as on the expected multinational's employment in the emerging market. Consequently, the multinational will opt to invest in more stable emerging markets. High enough instability in the emerging market producing the intermediate input would induce the multinational to diversify the production location. This strategy will increase the footlessness of the multinational, channeling the expected employment from the original producer of the intermediate product, to the benefit of other emerging markets.

A simplifying assumption allowing more tractable analysis was that the labor force is competitive and homogenous. A draw back of this assumption is that employment changes in sector M (the intermediate input) do not impact the welfare of the emerging market. This result can be easily modified, so that higher employment by the multinational is welfare enhancing. For example, if the labor is heterogeneous in the skills employed by the multinational, all the infra marginal workers earn a quasi rent for their skills [see Appendix B for a review of this extension]. This rent increases with multinational employment. Alternatively, if the labor is unionized, it will obtain part of the rents. In both cases, higher expected employment by the multinational would be associated with larger labor's quasi rents, increasing the GNP. Finally, the paper's model can be extended to allow for a large number of multinationals' activities with heterogeneous supply and demand conditions. It can be shown that, in such an extended model, higher volatility in a developing country is associated with a drop in the FDI inflow to that economy. 


\section{Appendix}

A. The purpose of this Appendix is to derive several equations used in the paper.

Mode I, Equations (10)-(11)

Substituting (5) - (7) into (8), we find that

$$
\Pi_{I}=3 A Y^{\delta}-\left[\frac{3 Y}{(1+\varepsilon) b}\right]^{2}-w_{1}^{*}\left[\frac{3 Y}{\left(1+\varepsilon_{1}^{*}\right) b_{1}^{*}}\right]^{2}-C
$$

where $Y$ denotes the consumption level in each country. The first-order condition characterizing optimal output $(\tilde{Y})$ and the resultant profits are

$$
\begin{aligned}
& \tilde{Y}=\left[\frac{\delta A}{6}\left(\Omega_{I}\right)^{-1}\right]^{\frac{1}{2-\delta}} ; \text { where } \Omega_{I}=[(1+\varepsilon) b]^{-2}+w_{1}^{*}\left[\left(1+\varepsilon_{1}^{*}\right) b_{1}^{*}\right]^{-2} \\
& \Pi_{I}=3 A \tilde{Y}^{\delta}\{1-0.5 \delta\}-C .
\end{aligned}
$$

The profits can be rewritten as

$$
\Pi_{I}=k_{I}\left[\theta_{I}(1+\varepsilon)^{-2}+\theta_{I}^{*}\left(1+\varepsilon_{1}^{*}\right)^{-2}\right]^{-\phi}-C
$$

where

$$
\begin{aligned}
& \phi=\frac{\eta-1}{\eta+1} ; \quad k_{I}=(1-0.5 \delta) 3 A(A \delta / 6)^{\phi}\left[(b)^{-2}+w_{1}^{*}\left(b_{1}^{*}\right)^{-2}\right]^{-\phi} ; \\
& \theta_{I}=\frac{(b)^{-2}}{(b)^{-2}+w_{1}^{*}\left(b_{1}^{*}\right)^{-2}} ; \theta_{I}^{*}=\frac{w_{1}^{*}\left(b_{1}^{*}\right)^{-2}}{(b)^{-2}+w_{1}^{*}\left(b_{1}^{*}\right)^{-2}} ; \theta_{I}+\theta_{I}^{*}=1
\end{aligned}
$$

Applying (5) and (6) and (A2) we infer that 


$$
L_{M, 1}^{*}=L_{M, 1}^{0}\left[\left\{\theta_{I}(1+\varepsilon)^{-2}+\theta_{I}^{*}\left(1+\varepsilon_{1}^{*}\right)^{-2}\right\}^{-2 \phi / \delta}\left(1+\varepsilon_{1}^{*}\right)^{-2}\right]
$$

where $L_{M, 1}^{0}$ is the demand for labor employed in producing $\mathrm{M}$ when all shocks are zero. Equations (10) and (11) follow from (A3) and (A5).

\section{Equations (12), (13). Mode $I I$}

The multinational determines the employment in the two emerging markets by minimizing the cost of production --

$$
\begin{aligned}
& \operatorname{Min}\left[\left\{w_{1}^{*} L_{M, 1}^{*}+w_{2}^{*} L_{M, 2}^{*}\right\}-\lambda\left\{\begin{array}{l}
\left(1+\varepsilon_{1}^{*}\right) b_{1}^{*} \sqrt{L_{M, 1}^{*}}+ \\
\left(1+\varepsilon_{2}^{*}\right) b_{2}^{*} \sqrt{L_{M, 1}^{*}}-3 \widetilde{Y}
\end{array}\right\}\right] \\
& L_{M, 1}^{*} ; L_{M, 2}^{*}
\end{aligned}
$$

Hence, it equates the marginal cost in the two locations:

$$
\frac{w_{1}^{*} \sqrt{L_{M, 1}^{*}}}{\left(1+\varepsilon_{1}^{*}\right) b_{1}^{*}}=\frac{w_{2}^{*} \sqrt{L_{M, 2}^{*}}}{\left(1+\varepsilon_{2}^{*}\right) b_{2}^{*}}
$$

Substituting (7) and (A7) into (9), collecting terms, we find that

$$
\begin{aligned}
& \Pi_{I I}=3 A Y^{\delta}-\left[\frac{3 Y}{(1+\varepsilon) b}\right]^{2}-\frac{(3 Y)^{2}}{\Omega^{*}}-C(1+f) \\
& \text { where } \Omega_{I I}^{*}=\left(1+\varepsilon_{1}^{*}\right)^{2} \frac{\left(b_{1}^{*}\right)^{2}}{w_{1}^{*}}+\left(1+\varepsilon_{2}^{*}\right)^{2} \frac{\left(b_{2}^{*}\right)^{2}}{w_{2}^{*}}
\end{aligned}
$$

The first-order condition characterizing the optimal output $(\widetilde{Y})$ and the resultant profits are 


$$
\begin{aligned}
& \widetilde{Y}_{I I}=\left[\frac{\delta A}{6}\left(\Omega_{I I}\right)^{-1}\right]^{\frac{1}{2-\delta}} ; \text { where } \Omega_{I I}=[(1+\varepsilon) b]^{-2}+\left(\Omega_{I I}^{*}\right)^{-1} \\
& \Pi_{I I}=3 A \widetilde{Y}^{\delta}\{1-0.5 \delta\}-C(1+f) .
\end{aligned}
$$

The profits can be rewritten as

$$
\Pi_{I I}=k_{I I}\left[\theta_{I I}(1+\varepsilon)^{-2}+\theta_{I I}^{*}\left\{\left(1+\varepsilon_{1}^{*}\right)^{2} \lambda_{1}^{*}+\left(1+\varepsilon_{2}^{*}\right)^{2} \lambda_{2}^{*}\right\}^{-1}\right]^{1-\phi}-C(1+f)
$$

where, using the notation $\mathrm{B}^{*}=\left(b_{1}^{*}\right)^{2} / w_{1}^{*}+\left(b_{2}^{*}\right)^{2} / w_{2}^{*}$,

$$
\begin{aligned}
& k_{I I}=(1-0.5 \delta) 3 A\left[\frac{A \delta}{6}\right]^{\phi}\left[(b)^{-2}+\left[B^{*}\right]^{-1}\right]^{-\phi}, \\
& \lambda_{1}^{*}=\frac{\left(b_{1}^{*}\right)^{2} / w_{1}^{*}}{\mathrm{~B}^{*}} ; \lambda_{2}^{*}=\frac{\left(b_{2}^{*}\right)^{2} / w_{2}^{*}}{\mathrm{~B}^{*}} ; \theta_{I I}=\frac{(b)^{-2}}{(b)^{-2}+\left[\mathrm{B}^{*}\right]^{-1}} ; \theta_{I I}^{*}=\frac{\left[\mathrm{B}^{*}\right]^{-1}}{(b)^{-2}+\left[\mathrm{B}^{*}\right]^{-1}} .
\end{aligned}
$$

Applying (9) and (A7) we infer that the employment in the foreign country is

$$
L_{M, 1}^{*}=L_{M, 1}^{0, d}\left(\theta_{I I}(1+\varepsilon)^{-2}+\theta_{I I}^{*}\left\{\left(1+\varepsilon_{1}^{*}\right)^{2} \lambda_{1}^{*}+\left(1+\varepsilon_{2}^{*}\right)^{2} \lambda_{2}^{*}\right\}^{-1}\right)^{-2 \phi / \delta} \frac{\left(1+\varepsilon_{1}^{*}\right)^{-2}}{\left(1+\varepsilon_{1}^{*}\right)^{2} \lambda_{1}^{*}+\left(1+\varepsilon_{2}^{*}\right)^{2} \lambda_{2}^{*}}
$$

where $L_{M, 1}^{0, d}$ is the demand for labor employed in sector $\mathrm{M}$ in country 1 under the diversified production, when all shocks are zero. Equations (12) and (13) follow from (A10) and (A11). 
B. The purpose of this Appendix is to extend the paper's model to the case of heterogeneous labor in the emerging market. This is done by reinterpreting the labor employed in sector M, $L_{M, i}^{*}$, implementing Rosen's (1978) aggregation of heterogeneous skills. Specifically, suppose that a worker $\mathrm{j}$ in country $\mathrm{i}$ can supply $l_{M, j, i}^{*}$ effective labor services in sector M, and 1 unit of labor service in sector Z. The Ricardian technology in sector $\mathrm{Z}$ implies that the wage in that sector is $a_{i}^{*}$, whereas the wage in sector M, dented by $w_{M, i}^{*}$, is endogenously determined. Let us define the relative wage in the two sectors by (B1) $\omega_{i}^{*}=a_{i}^{*} / w_{M, i}^{*}$

Let the density function of skills in sector M be $f\left(l_{M, i}^{*}\right)$, measuring the number of workers whose skills can yield labor services of $l_{M, i}^{*}$ in sector M. A worker $\mathrm{j}$ would supply effort to sector $\mathrm{M}$ if

(B2) $l_{M, j, i}^{*} w_{M, i}^{*}>a_{i}^{*}$.

Alternatively, if

(B2') $l_{M, j, i}^{*}>\omega_{i}^{*}$

Hence, the total labor services supplied to sector $\mathrm{M}$ at the given relative wage $\omega_{i}^{*}$ is the sum of all the supply of workers whose productivity in M exceeds the relative wage:

$$
L_{M, i}^{*}=\int_{\omega_{i}^{*}}^{\infty} x f(x) d x .
$$

Recalling that the wage in sector $Z$ is given by $a_{i}^{*}$, we can solve (B3) to infer the wage in sector M needed to support employment $L_{M, i}^{*}$ :

$$
w_{M, i}^{*}=w_{M, i}^{*}\left(L_{M, i}^{*}\right) ; \quad \frac{d w_{M, i}^{*}}{d L_{M, i}^{*}}=\frac{w_{M, i}^{*}}{\left[\omega_{i}^{*}\right]^{2} f\left(\omega_{i}^{*}\right)}>0 .
$$

Equations (1)-(7) continue to apply. The multinational's problem is modified to account for the endogenous determination of the manufacturing wage. Specifically, the multinational is maximizing the expected value of (8) and (9) (in modes I and II respectively), with the added constraint that the wage in sector $\mathrm{M}$ is linked to the employment in that sector via 
(B4). All the qualitative results of the paper continue to apply, with the modification that the GNP of the emerging markets depends positively on the employment in M. Specifically, the GNP in country $i$ is

$$
G N P_{i}^{*}=a_{i}^{*} \int_{0}^{\omega_{i}^{*}} f(x) d x w_{i}^{*}+w_{M, i}^{*} \int_{\omega_{i}^{*}}^{\infty} x f(x) d x .
$$

Hence,

(B6) $\frac{d G N P_{i}^{*}}{d L_{M, i}^{*}}=\frac{d w_{M, i}^{*}}{d L_{M, i}^{*}} L_{M, i}^{*}=\frac{w_{M, i}^{*} L_{M, i}^{*}}{\left[\omega_{i}^{*}\right]^{2} f\left(\omega_{i}^{*}\right)}>0$.

Higher employment in sector $M$ requires higher wages there, needed to attract the marginal worker from $\mathrm{Z}$ to $\mathrm{M}$. This wage hike increases the 'quasi rent' of all the inframarginal workers that are already employed in that sector, increasing thereby the GNP. 


\section{References}

Aizenman, J. 1994, "Monetary and real shocks, productive capacity and exchange rate regimes," Economica, November, 407-34.

Aizenman, J. and N. P. Marion, "The Merits of Horizontal versus Vertical FDI in the Presence of Uncertainty", November 2001.

Blonigen, Bruce. 1997, "Firm-Specific Assets and the Link Between Exchange Rates and Foreign Direct Investment," American Economic Review 87, June, 447-466.

Brainard, S. L., 1997, “An Empirical Assessment of the Proximity-Concentration Tradeoff between Multinational Sales and Trade," American Economic Review 87, 520-544.

Carr, David L., James R. Markusen and Keith E. Maskus, 2001, "Estimating KnowledgeCapital Model of the Multinational Enterprise," American Economic Review 91, No.3 (June), 693-708.

Dunning, J. H., 1993, Multinational Enterprises and the Global Economy, Addison Wesley.

Feenstra, Robert C. and Gordon H. Hanson, 1997, "Foreign Direct Investment and Relative Wages: Evidence from Mexico's Maquiladoras," Journal of International Economics, Vol. 42: 371-394.

Froot, Ken and J. Stein, 1991, "Exchange Rates and Foreign Direct Investment: An Imperfect Capital Markets Approach," Quarterly Journal of Economics 106, 11911217.

Goldberg, L. S. and Kolstad, C. D., 1995, "Foreign Direct Investment, Exchange Rate Variability and Demand Uncertainty," International Economic Review, vol 36, no.4, pp.855-873.

Hausmann, Ricardo and Michael Gavin, 1995, “Overcoming Volatility,” Part II of Economic and Social Progress in Latin America, Inter-American Development Bank.

Helpman, Elhanan. 1984, "A Simple Theory of Trade with Multinational Corporations," Journal of Political Economy 92, 451-471. and Paul Krugman, 1985, Market Structure and International Trade, MIT Press.

Klein, Michael and Eric Rosengren, 1994, “The Real Exchange Rate and Foreign Direct Investment in the United States: Relative Wealth vs. Relative Wage Effects," Journal of International Economics 36, 373-389. 
Markusen J. R., 1984, Multinationals, Multi-Plant Economies and the Gains from Trade, Journal of International Economics 16, 205-226.

Markusen J. R. and K. E. Maskus, 2001, "General-Equilibrium Approaches to the Multinational Firm: A Review of Theory and Evidence,” NBER WP No. 8334.

Rosen, Sherwin, 1978, "Substitution and Division of Labor," Economica.

Spiegel, M. Mark, 1994, “Sovereign Risk Exposure With Potential Liquidation: The Performance of Alternative Forms of Financing," Journal of International Money and Finance, 400-414.

Wei, Shang-Jin, 1997, "Why is Corruption So Much More Taxing Than Tax? Arbitrariness Kills," NBER Working Paper No. 6255. 


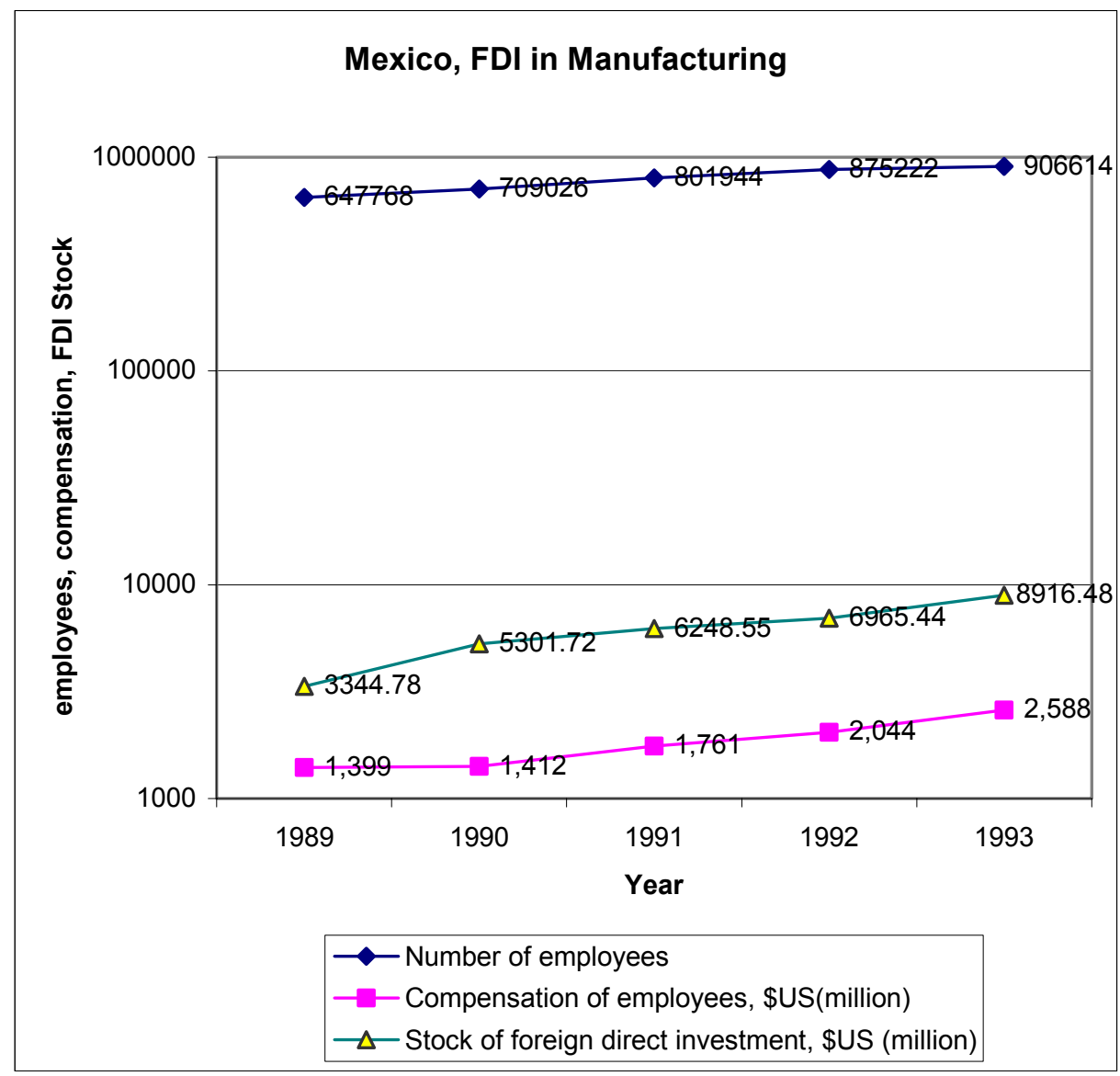

Figure 1

Multinational Manufacturing employment, investment and compensation, 1989-1993

Source: Measuring Globalization, The Role of Multinationals in OECD Economics, 2001 

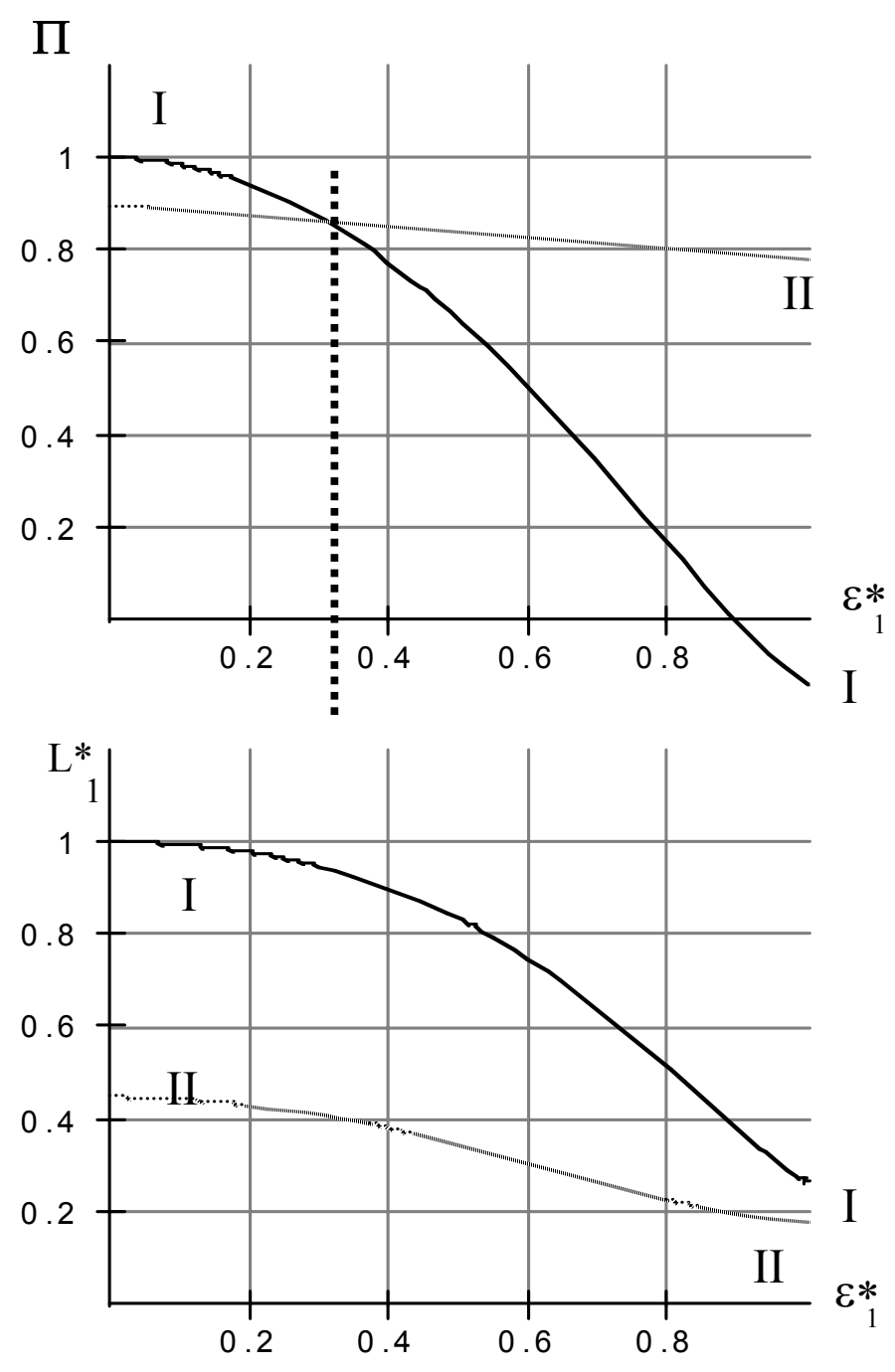

Figure 2

Volatility, expected profits and expected employment in $\mathrm{F}_{1}$ - low margins

The expected profits are reported as a fraction of the mode $I$ profits in the absence of volatility. The expected employment are reported as a fraction of the employment in mode $I$ in the absence of volatility.

Drawn for the case where $\delta=0.75 ; \varepsilon_{2}^{*}=0.4 ; A=1 ; C=0.25 ; f=0.3$. 


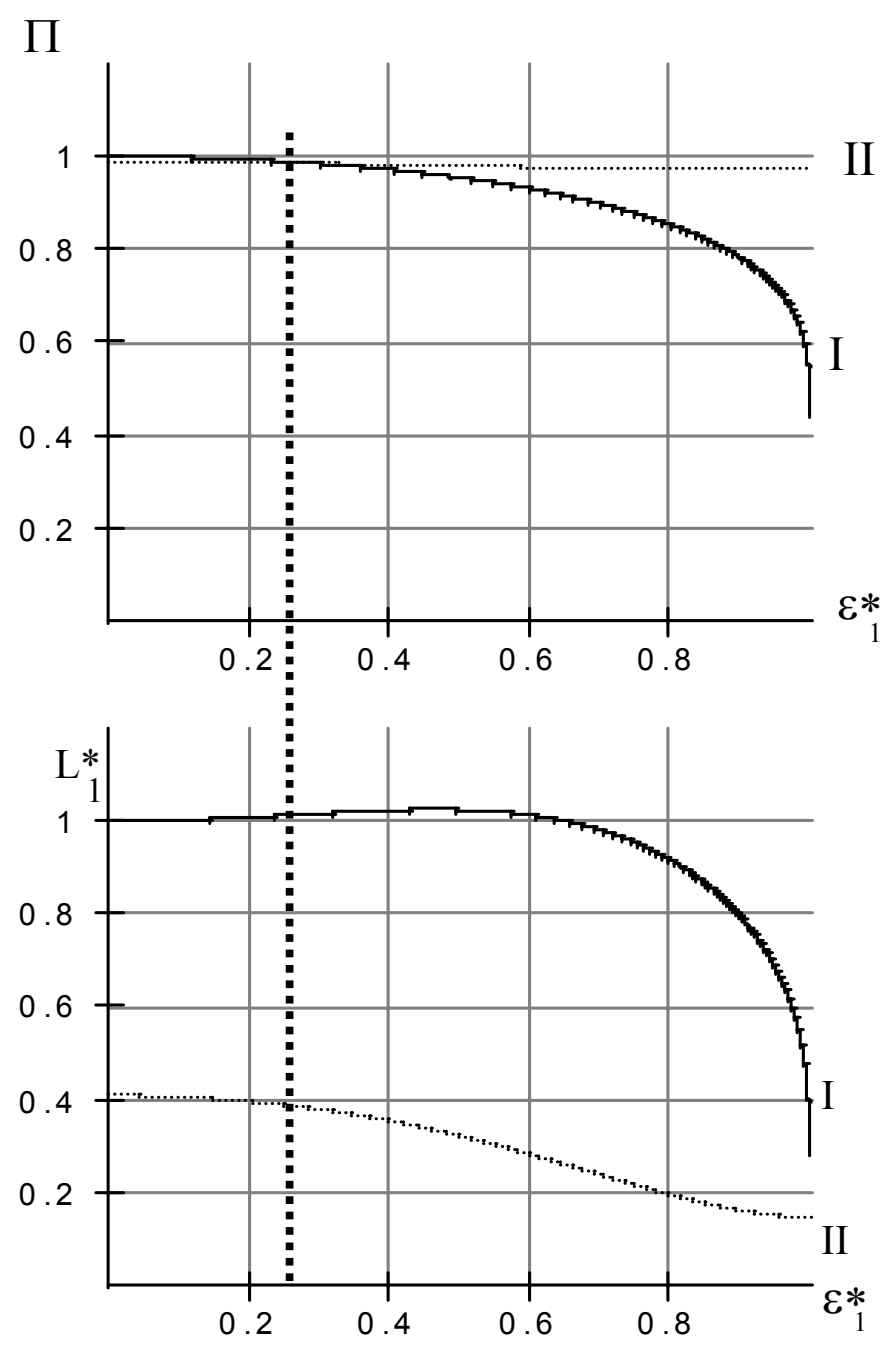

Figure 3

\section{Volatility, expected profits and expected employment in $\mathrm{F}_{1}$ - high margins}

The expected profits are reported as a fraction of the mode I profits in the absence of volatility. The expected employment are reported as a fraction of the employment in mode I in the absence of volatility.

Drawn for the case where $\delta=0.25 ; \varepsilon_{2}^{*}=0.4 ; A=1 ; C=0.25 ; f=0.3$. 